\title{
Incidence and Clinical Significance of Junctional Rhythm Remaining After Termination of Radiofrequency Current Delivery in Patients With Atrioventricular Nodal Reentrant Tachycardia
}

\author{
Naomi Kawaguchi, MD; Yoshinori Kobayashi, MD; Yasushi Miyauchi, MD; \\ Hirotsugu Atarashi, MD; Teruo Takano, MD; Hirokazu Hayakawa, MD
}

\begin{abstract}
The aim of this study was to elucidate the electrophysiologic characteristics and clinical significance of the accelerated junctional rhythm (JR) that remains after termination of radiofrequency (RF) current delivery during catheter ablation (CA) for atrioventricular nodal reentrant tachycardia (AVNRT). Fifty consecutive patients with AVNRT (21M, 29F, age 48 years) underwent RF-CA targeting the slow pathway. JR occurred at 124 out of a total of 236 ablation sites (53\%) during the RF delivery. With $15 \mathrm{RF}$ deliveries $(6.4 \%, \mathrm{n}=10)$, JR remained after termination of the RF delivery (Post-JR). The mean cycle length of the Post-JR immediately after termination of the RF delivery was $639 \pm 124 \mathrm{~ms}$ and its duration was widely distributed from $3 \mathrm{~s}$ to more than $1 \mathrm{~h}$. The Post-JR exhibited a spontaneous rate deceleration and overdrive suppression by rapid atrial pacing. The JR during the RF delivery followed by Post-JR had a greater time span in which the JR appeared, compared with that without Post-JR. The Post-JR had less sensitivity(18 vs $96 \%$ ), but greater specificity (97 vs 59\%) and a positive predictive value (60 vs 39\%) in predicting successful ablation compared with JR seen only during the RF delivery. It is concluded that the presence of Post-JR might be a reflection of the intense effect of RF energy on the nodal or peri-nodal tissue. (Jpn Circ J 1999; 63: 865-872)
\end{abstract}

Key Words: Accelerated junctional rhythm; Atrioventricular nodal reentrant tachycardia; Koch's triangle; Radiofrequency catheter ablation

$\mathbf{E}$ mergence of accelerated junctional rhythm (JR) during radiofrequency (RF) current delivery directed at the peri-atrioventricular (AV) nodal region has been shown to be a marker of successful catheter ablation in AV nodal reentrant tachycardia (AVNRT), ${ }^{1-6}$ and has been considered as a response of the AV node to the thermal injury of either the nodal or perinodal tissue, 6.7 It has also been shown that there is an important thermal latency between the catheter tip-tissue interface and the intramural region (ie, although the tip temperature drops instantly at termination of the RF pulse, the tissue temperature continues to rise and/or remains significantly higher than the tip temperature during the post-RF period) $)^{8-10}$ Therefore, on the basis of the theory that the appearance of JR is a reflection of the thermal effect on the AV node or its transitional cells to the atrial muscle, it is conceivable that the JR may persist even after cessation of RF current delivery and continue until the thermal effect dissipates. In fact, it is sometimes observed that junctional tachycardia temporarily remains as an ectopic cardiac pacemaker overriding the sinus rhythm after termination of the RF delivery 4,11 The characteristics of accelerated JR during RF current delivery have already been evaluated in

(Received April 7, 1999; revised manuscript received July 12, 1999; accepted August 2, 1999)

First Department of Internal Medicine, Nippon Medical School, Tokyo, Japan

Mailing address: Yoshinori Kobayashi, MD, The First Department of Internal Medicine, Nippon Medical School, 1-1-5 Sendagi, Bunkyoku, Tokyo 113-8603, Japan association with the outcome of catheter ablation (CA) and inadvertent development of an AV conduction disturbance (AV block) ${ }^{3-6}$ However, the electrophysiologic features and significance of the JR seen in the post-RF period (PostJR) have not yet been clarified. The aim of the present study was to elucidate the characteristics and determine the clinical significance of the presence of Post-JR.

\section{Methods}

\section{Patient Population}

The study population was comprised 50 consecutive patients with recurrent episodes of AVNRT referred for RF-CA between August 1994 and October 1997. There were 21 males and 29 females with a mean age of $48 \pm 17$ years (range, 17-73). Forty eight patients had common (slow-fast) type AVNRT, and the remaining 2 patients had the uncommon (fast-slow) type. The patients had been treated with a mean of $1.2 \pm 1.1$ antiarrhythmic drugs including class I and class IV antiarrhythmic agents of the Vaughan Williams classification. However, these agents were unsuccessful in suppressing the occurrence of paroxysmal tachycardias. Four patients had coronary heart disease, 4 had hypertensive heart disease, and 1 had mitral valve disease. The remaining 41 patients had no evidence of structural heart disease.

\section{Electrophysiologic Study}

All patients were informed of the invasive nature of the $\mathrm{CA}$ procedure and anticipated complications. After written 


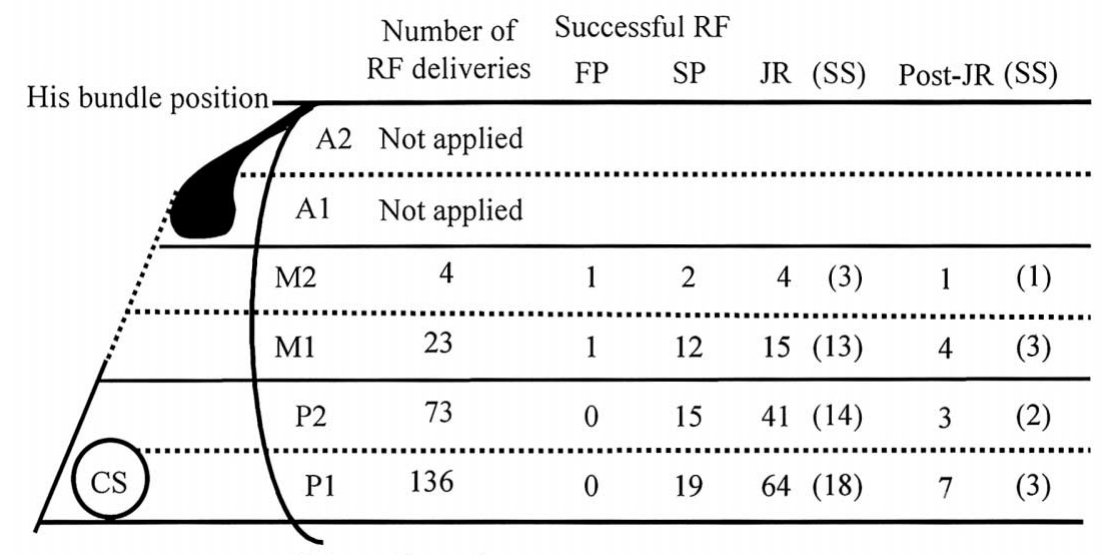

Tricuspid annulus
Fig 1. Schematic illustration of the location of all ablation sites and the 50 successful ablation sites divided into fast and slow pathway ablation (Left), the location of the ablation sites where accelerated junctional rhythm was seen during the RF deliveries (Middle), and the location of the ablation sites where junctional rhythm remained after termination of the RF deliveries (Right). The number of successful ablation sites are shown in parentheses. Note that the sites with Post-JR were located in the posteromedial region of Koch's triangle, similar to the sites with junctional rhythm during the RF delivery. FP, number of fast pathway ablation; SP, number of slow pathway ablation; JR, accelerated junctional rhythm during RF current delivery; Post-JR, accelerated junctional rhythm remaining after the RF current delivery; SS, number of successful ablation sites. informed consent was obtained, each patient underwent a standard diagnostic electrophysiologic (EP) study before the CA session. The EP study was performed in the fasting state after antiarrhythmic agents had been discontinued for at least 5 half lives. Two 7F quadripolar catheters were inserted into the right femoral vein and positioned at the high right atrium and right ventricular apex. One $6 \mathrm{~F}$ quadripolar catheter (2-5-2 interelectrode spacing) was also inserted into the right femoral vein and positioned at the His bundle region. One $6 \mathrm{~F}$ decapolar catheter (2-8-2 interelectrode spacing) was inserted into either the right internal jugular vein or subclavian vein and advanced into the coronary sinus with the proximal pair of electrodes just at the coronary sinus ostium. Intracardiac signals were amplified and filtered from 30 to $500 \mathrm{~Hz}$ (E for M, V600 or EP Lab) and the data were recorded on an optical disk (EP Lab, Quinton Instrument Co). Atrial and ventricular incremental pacing and programmed stimulation, including the single and double extrastimulus method, were performed with twice the diastolic threshold to determine the inducibility of AVNRT. If the tachycardia could not be induced or if the induced AV nodal reentry did not perpetuate, then a similar pacing protocol was repeated under continuous intravenous infusion of isoproterenol $\left(0.0025-0.01 \mu \mathrm{g} \mathrm{kg}^{-1} \mathrm{~min}^{-1}\right)$, which was continued until the end of the CA session. AVNRT was diagnosed from previously established criteria!2 The induced tachycardias were common AV nodal reentry (slow-fast) in 48 patients, and both common and uncommon (fast-slow) in 2 patients. The mean cycle length of the induced tachycardia was $363 \pm 70 \mathrm{~ms}$. Dual AV nodal physiology, defined as positive jump-up phenomenon of the atrio-His $(\mathrm{AH})$ interval during the decremental extrastimulus method (ie, abrupt prolongation of the $\mathrm{AH}$ interval by more than $50 \mathrm{~ms}$ as the coupling interval was shortened by $10 \mathrm{~ms}$ ) was present in 43 patients, whereas in the remaining 7 patients the atrioventricular conduction curves showed consistent smooth curves. The effective refractory periods of the fast pathway and slow pathway were $382 \pm 90$ and $264 \pm 57 \mathrm{~ms}$, respectively.

\section{Radiofrequency Catheter Ablation}

Catheters for Ablation Seven or 8 French bi- or quadri-polar catheters with a 4-mm large tip electrode were used.

$R F$ Generator In the initial 17 sessions, we used 500$\mathrm{kHz}$ generators only capable of the power control mode. In the remaining sessions (34 sessions), generators with a closed-loop temperature control system were used.

RF Delivery While using the power-controlled generators, the RF current was delivered from 15 to $30 \mathrm{~W}$ between a large-tip electrode and an adhesive electrosurgical dispersive pad applied to the left back underneath the scapula. The current delivery was terminated immediately in the event of an impedance rise or displacement of the catheter electrode. Otherwise, RF current delivery was maintained for $60 \mathrm{~s}$. For the more recent patients, when the temperature control system was used, the initial target temperature was always set at $60^{\circ} \mathrm{C}$. The power output automatically shutdown if the tip temperature exceeded the target temperature by $8-10^{\circ} \mathrm{C}$, or if the impedance exceeded $250 \Omega$. The RF current delivery was also immediately stopped when ventriculo-atrial block of accelerated JR was observed during the RF application.

\section{Target Sites for Catheter Ablation}

In the first 2 patients only, the anatomical approach was used to ablate the slow pathway 2 . The tricuspid annulus between the coronary sinus ostium and the His bundle recording site was divided into the posterior, medial and anterior regions and each of these 3 regions were divided into 2 subsections (Fig 1). Serial RF energy applications were delivered along the tricuspid annulus, starting at position P1 and moving up sequentially to position A2. In the remaining 48 patients, the target sites were determined with the electrogram mapping approach. The areas along the posteromedial tricuspid annulus were mapped and slow pathway potentials were searched. We considered there to be a slow pathway potential if a discrete potential of either the low-high frequency type ${ }^{13}$ or high-low frequency type, or a mixture of these 2 types, intervened between the atrial and ventricular potentials.

The inducibility of AVNRT was assessed after each application of RF energy delivery using programmed atrial stimulation including single and double extrastimuli. The end point of the CA session was the elimination of the slow pathway conduction, or the inability to induce repetitive AV nodal reentrant beats ( $\geq 3$ beats) with persistence of dual AV nodal physiology, both before and during isoproterenol infusion $\left(0.0025-0.01 \mu \mathrm{g} \mathrm{kg}^{-1} \mathrm{~min}^{-1}\right)$.

\section{Estimated Variables of the Junctional} Rhythm During RF Current Delivery

The following variables of the JR were assessed and compared between successful and unsuccessful RF appli- 
Table 1 List of Patients and RF Deliveries With Post Junctional Rhythm

\begin{tabular}{|c|c|c|c|c|c|c|c|c|c|}
\hline Patient no & RF. no & $\begin{array}{l}\text { Age } \\
\text { (years) }\end{array}$ & Sex & $\begin{array}{l}\text { Ablation } \\
\text { site }\end{array}$ & $\begin{array}{l}\text { Duration of } \\
\text { Post-JR (s) }\end{array}$ & $\begin{array}{l}\text { CL of Post- } \\
\quad J R(m s)\end{array}$ & $\begin{array}{c}\text { SCL before RF } \\
\text { delivery }(m s)\end{array}$ & $\begin{array}{c}I S P \\
\left.\mu g \mathrm{~kg}^{-1} \mathrm{~min}^{-1}\right)\end{array}$ & $\begin{array}{c}\text { Ablatopn } \\
\text { results }\end{array}$ \\
\hline 1 & 1 & 54 & $F$ & M2 & 9 & 670 & 700 & - & $S(F P)$ \\
\hline 2 & 1 & 60 & $M$ & M1 & 10 & 800 & 600 & 0.005 & $S(S P)$ \\
\hline 3 & 1 & 72 & $F$ & $P 1$ & 13 & 573 & 857 & 0.0075 & $S(S P)$ \\
\hline \multirow[t]{3}{*}{4} & 1 & 32 & $M$ & $P 1$ & 13 & 480 & 480 & - & $U S$ \\
\hline & 2 & & & M1 & 10 & 452 & 515 & 0.005 & $U S$ \\
\hline & 3 & & & M1 & 15 & 500 & 500 & 0.005 & $S(S P)$ \\
\hline 5 & 1 & 53 & $M$ & M1 & 23 & 540 & 423 & 0.00375 & $S(F P)$ \\
\hline \multirow[t]{2}{*}{6} & 1 & 54 & $F$ & $P 1$ & 3 & 840 & 615 & 0.0075 & US \\
\hline & 2 & & & $P 2$ & 60 & 600 & 620 & 0.0075 & $U S$ \\
\hline 7 & 1 & 39 & $F$ & $P 2$ & 14 & 575 & 750 & - & $S(S P)$ \\
\hline \multirow[t]{3}{*}{8} & 1 & 19 & $F$ & $P 1$ & 7 & 750 & 550 & - & US \\
\hline & 2 & & & P1 & 25 & 736 & 710 & 0.0015 & $U S$ \\
\hline & 3 & & & $P 1$ & 1800 & 645 & 710 & 0.0015 & $S(S P)$ \\
\hline 9 & 1 & 26 & $F$ & $P 1$ & 3600 & 653 & 950 & 0.005 & $S(S P)$ \\
\hline 10 & 1 & 20 & $F$ & $P 2$ & $>3600$ & 544 & 700 & 0.001 & $S(S P)$ \\
\hline
\end{tabular}

Ablation site, represented as 6 divided portions of koch's triangle as shown in Fig 1. CL, cycle length; SCL, sinus cycle length; ISP, isproterenol; S, successful; US, unsuccessful; FP, fast pathway; SP, slow pathway.

cations, and between the RF applications followed by PostJR and those without.

(1) Total time span during which JR appeared, calculated by the following equation: (time of appearance of JR/ time of RF current delivery) $\times 100 \%$.

(2) Duration of individual bursts of JR, defined as the longest duration of bursts of JR that intermittently appeared during RF current delivery.

(3) Mean cycle length of the JR.

\section{Statistical Analysis}

All data are expressed as mean value \pm 1 SD. Comparisons were performed using the Student's t test or by the chi-square test. A value of $\mathrm{p}<0.05$ was considered statistically significant.

\section{Results}

\section{Outcome of the Catheter Ablation}

At the end of the CA session, all patients had a successful outcome. The mean number of RF current deliveries was $4.6 \pm 4.2$, and the cumulative energy was $5840 \pm 5850 \mathrm{~J}$.

Anatomical Approach In 1 patient, RF energy delivery directed at the M2 zone resulted in the fast pathway ablation (patient no. 1 in Table 1). In the remaining patient, slow pathway ablation was achieved.

Electrical Mapping Approach The CA procedures using the electrogram mapping approach produced a unidirectional effects on the fast pathway conduction in only 1 patient; that is, retrograde conduction via the fast pathway was selectively eliminated. The slow pathway was preferentially affected by this approach in the majority of patients: slow pathway ablation (defined as elimination of the jump-up phenomenon) in 22 patients, and slow pathway modification (defined as residual slow pathway conduction but the inability to induce repetitive AV nodal echo beats ( $\geq 3$ beats)) in 26 patients.

The location of the effective target sites of the successful ablations in the 50 patients are depicted in Fig 1 . The RF energy application in the M2 zone produced fast pathway ablation in 1, and slow pathway modification in 2 patients. In contrast, most RF current deliveries applied to the posterior portion resulted in either slow pathway ablation or modification. These results were consistent with those of previous reports 2,6

During the follow-up period, ranging from 18 to 60 months, AVNRT recurred in 2 patients, one of whom showed a short-term Post-JR during the CA session.

\section{Accelerated JR During RF Current Delivery}

Junctional rhythm appeared during 48 of $50(96 \%)$ successful CA attempts, and in only 76 of 186 unsuccessful attempts (30\%). The overall incidence of JR was 124/236 sites $(53 \%)$. The sensitivity and specificity of the JR during the RF current applications in predicting a successful outcome were $96.0 \%$ and $59.1 \%$, respectively. Consequently, the positive predictive value was $38.7 \%$. Compared with the ineffective RF current applications, the successful RF current applications had a significantly greater total time span during which JR appeared, $(56 \pm 28$ vs $41 \pm 30 \%, p<0.05)$ and tended to have a longer duration of individual bursts of JR $(21 \pm 16$ vs $16 \pm 15 \mathrm{~s}, \mathrm{p}=0.11)$. The mean cycle length of the accelerated JR did not significantly differ between these 2 groups (571 \pm 141 vs $614 \pm 171$ $\mathrm{ms}, \mathrm{p}=0.48$ ).

\section{Junctional Rhythm Remaining After Termination of the RF Current Delivery (Post-JR)}

In 15 of $236 \mathrm{RF}$ current deliveries $(6.4 \%, \mathrm{n}=10)$, junctional tachycardia persisted after cessation of the RF application. The Post-JR always succeeded the JR occurring during the RF current delivery, which lasted to the end of the delivery. No Post-JR spontaneously developed during the post-RF period. The patients with Post-JR and the electrophysiologic characteristics of the Post-JR are listed in Table 1. The duration of the Post-JR was widely distributed from $3 \mathrm{~s}$ to $1 \mathrm{~h}$. The mean cycle length at the termination of the RF current delivery was $639 \pm 125 \mathrm{~ms}$. The ablation sites of positive Post-JR were predominantly located at the posteromedial region of Koch's triangle and their distribution was similar to that of the positive junctional tachycardia observed during the RF delivery (Fig 1). The clinical and electrophysiologic variables of the patients and RF deliveries with Post-JR are compared with those without Post-JR in Table 2. The clinical background, including age, gender, presence of structural heart disease and previously documented arrhythmias other than AVNRT, did not differ between the patients with Post-JR and those without. 
Table 2 Comparison of the Patient's Background and Ablation Variables

\begin{tabular}{|c|c|c|c|}
\hline & Post-JR (-) & Post-JR (+) & $p$ value \\
\hline Patient & $(n=40)$ & $(n=10)$ & \\
\hline Age (years) & $49=17$ & $43 \pm 18$ & NS \\
\hline Sex & $22 F / 18 M$ & $7 F / 3 M$ & $N S$ \\
\hline \multicolumn{4}{|l|}{ Structural heart disease } \\
\hline$I H D$ & 3 & 1 & $N S$ \\
\hline$H H D$ & 3 & 1 & \\
\hline$M V P$ & 1 & & \\
\hline \multicolumn{4}{|l|}{ Other previously documented arrhythmias } \\
\hline$P_{A} F$ & 8 & 1 & $N S$ \\
\hline$A T$ & 1 & & \\
\hline Maximum SNRT (ms) & $1240 \pm 290$ & $1280 \pm 380$ & $N S$ \\
\hline Maximum cSNRT (ms) & $380 \pm 150$ & $420 \pm 250$ & $N S$ \\
\hline Ablation variables & $(n=109)$ & $(n=15)$ & \\
\hline \multicolumn{4}{|l|}{ Delivery site } \\
\hline$M 2$ & 3 & 1 & $N S$ \\
\hline M1 & 11 & 4 & \\
\hline$P 2$ & 38 & 3 & \\
\hline P1 & 57 & 7 & \\
\hline RF current energy (Joule) & $1499 \pm 825$ & $1267 \pm 864$ & $N S$ \\
\hline Maximum tip temperature $\left({ }^{\circ} \mathrm{C}\right)$ & $57 \pm 8$ & $55 \pm 3$ & $N S$ \\
\hline Isoproterenol infusion during RF delivery & $57 / 109(52 \%)$ & $11 / 15(73 \%)$ & $N S$ \\
\hline SCL just before RF delivery ( $\mathrm{ms}$ ) & $706 \pm 158$ & $645 \pm 145$ & $N S$ \\
\hline
\end{tabular}

$I H D$, ischemic heart disease; $H H D$, hypertensive heart disease; $M V P$, mitral valve prolapse; $P_{A} F$, paroxysmal atrial fibrillation; AT, atrial Tachycardia; SNRT, sinus node recovery time; cSNRT, corrected sinus node recovery time; SCL, sinus cycle length; NS, not significant.

A

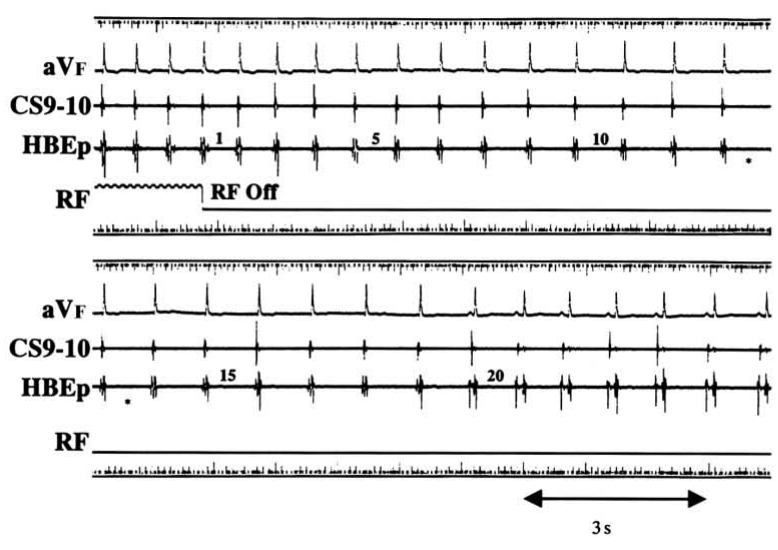

B

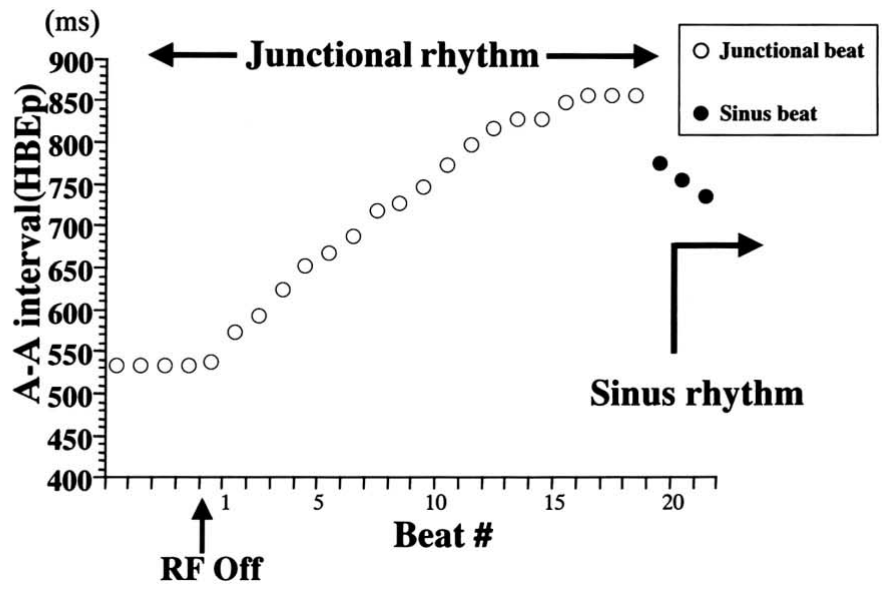

Fig 2. (A) Representative recording of junctional rhythm that remained for $14 \mathrm{~s}$ after termination of the RF delivery. Note that the cycle length of the junctional rhythm gradually prolonged during the time course of the post-RF period. (B) Depiction of the time-dependent change in the cycle length of the junctional rhythm at and after termination of RF delivery, constructed with the data of the left panel (A).

Maximum sinus node recovery time and corrected sinus node recovery time, assessed at the baseline study, were within the normal range in all patients of both groups, and there were no significant differences in those values between the 2 groups. With regard to the variables related to the RF deliveries, neither the RF energy nor the mean temperature of the tissue-electrode interface differed between the RF deliveries with Post-JR and those without. Furthermore, the sinus cycle length just before the start of the RF delivery did not significantly differ between the 2 groups either. Although there was not a significant difference, the JR tended to remain after the termination of RF delivery during intravenous infusion of isoproterenol (73\% vs $52 \%$ ). It is noted that all the RF applications followed by long-term Post-JR with durations longer than $1 \mathrm{~min}$ occurred under the administration of isoproterenol (Table 1).

\section{Electrophysiologic Features of the Post-JR}

A representative recording of the Post-JR with a relatively short duration is shown in Fig 2A. In this 39-year-old female patient (patient no.7), during an RF current delivery directed at the M1 zone, accelerated JR emerged $40 \mathrm{~s}$ prior to termination of the RF delivery and remained at the end of that RF delivery. It should be noted that JR remained even after termination of the RF application and overrode the sinus rhythm cycle length, and that the Post-JR lasted for only $14 \mathrm{~s}$ and was replaced by sinus rhythm as the dominating cardiac pacemaker as the cycle length of the JR gradually prolonged (Fig 2B). It is also noteworthy that the 
A

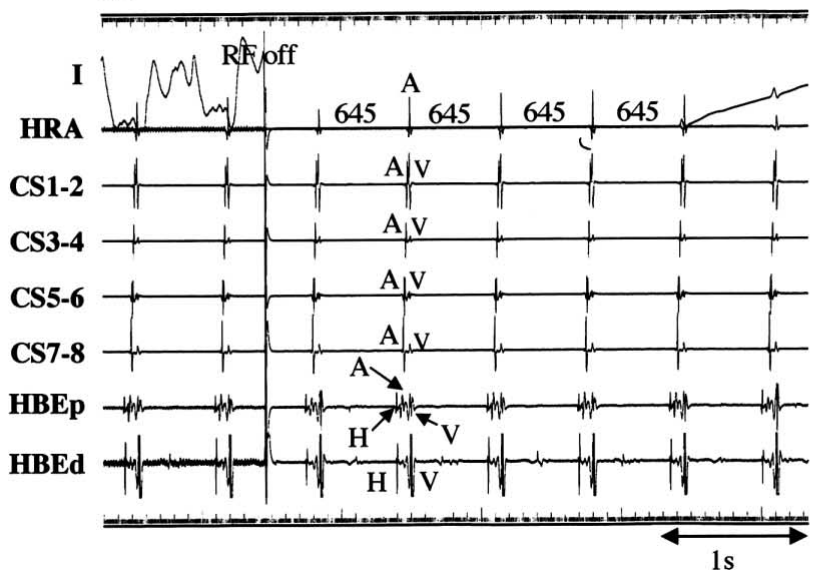

B

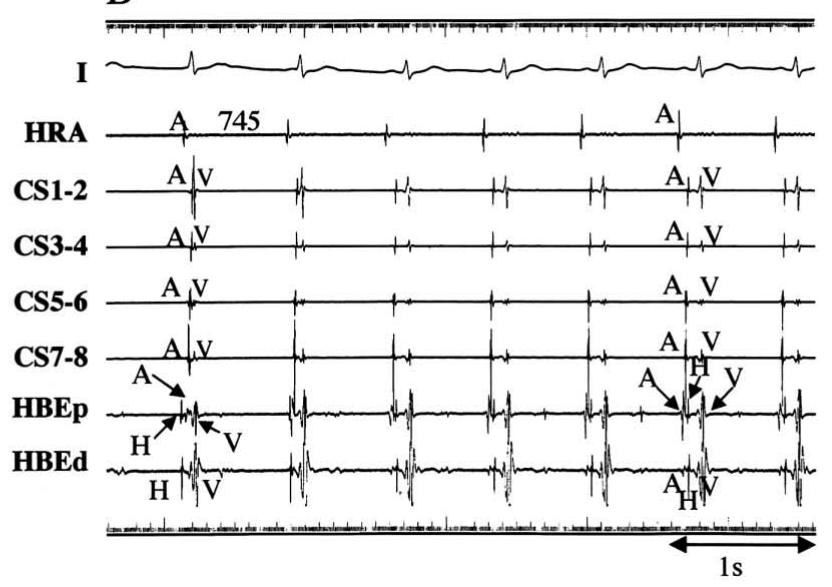

Fig 3. Representative recording of junctional rhythm that remained for a relatively long duration after termination of the RF delivery. (A) The cycle length of the Post-JR was $645 \mathrm{~ms}$ immediately after termination of the RF delivery. It gradually prolonged and was $685 \mathrm{~ms}$ at $2 \mathrm{~min}$ later (data not shown). (B) At $30 \mathrm{~min}$ after termination of the RF delivery, the Post-JR had prolonged to $750 \mathrm{~ms}$ and converted to sinus rhythm overriding the junctional rhythm.

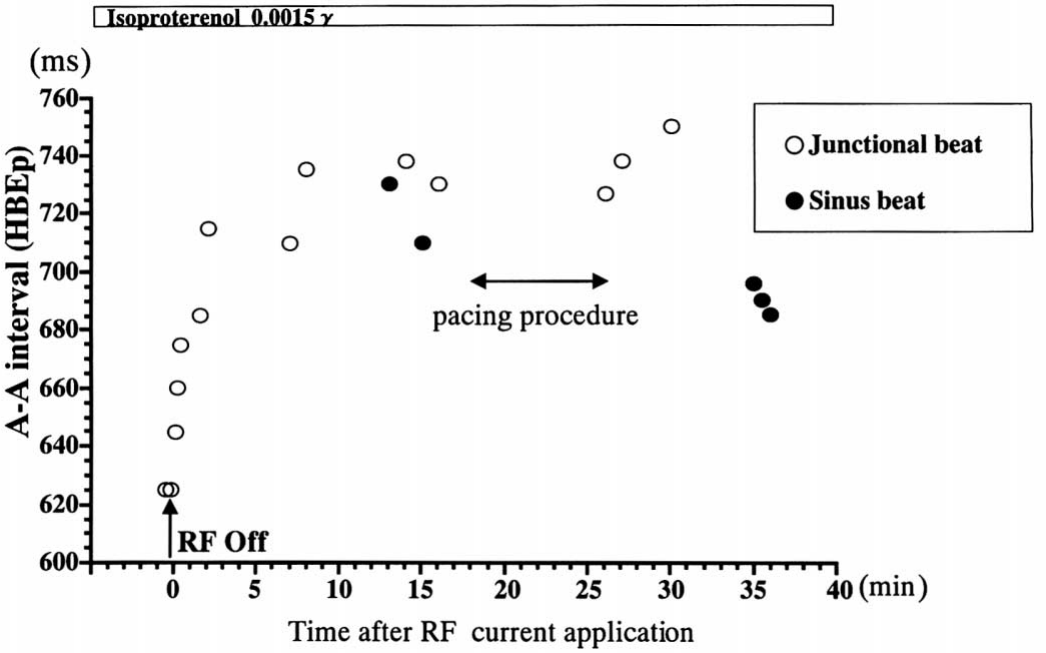

Fig 4. Depiction of the time course of the cycle length for long-term junctional rhythm at and after termination of the RF delivery, which was constructed with the data of a representative case (Fig 3). Note that sinus rhythm intermittently appeared while junctional rhythm was mainly the predominant cardiac rhythm during the post-RF period. Sinus rhythm finally became sustained at 30 min after the termination of the RF delivery.

atrial activation sequence of the JR did not change before and after the termination of the RF current delivery. This RF current application rendered the AVNRT noninducible. Most of the Post-JRs with a short duration had a similar time-course to this representative case both during and after the RF current delivery.

Another form of Post-JR was a JR that remained as a stable cardiac pacemaker for more than $1 \mathrm{~min}$, and very occasionally lasted for more than $1 \mathrm{~h}$, after termination of the RF delivery. A representative recording of such an extended time course of Post-JR is shown in Fig 3. In this 19-year-old female patient (patient no.9), the JR appeared $1.5 \mathrm{~s}$ after the start of the RF current delivery directed at the P1 zone and lasted till the end of the RF delivery. The cycle length of the Post-JR was $645 \mathrm{~ms}$ immediately after termination of the RF delivery (Fig 3A), and at 2 min post-RF it was $685 \mathrm{~ms}$. Finally, at $30 \mathrm{~min}$ post-RF, the Post-JR disappeared and converted to sinus rhythm overriding the JR (Fig 3B). The time course for the cycle length of the junctional rhythm during and after the RF application is depicted in Fig 4. Similarly with the short-term Post-JR (Fig 2), the cycle length gradually prolonged and was sustained for $30 \mathrm{~min}$. It was noted that sinus rhythm inter- mittently appeared while the Post-JR was mainly the predominant cardiac rhythm, and finally sinus rhythm became sustained from $30 \mathrm{~min}$ after the termination of the RF delivery. Fixed rate pacing with a cycle length of 330 ms applied from the high right atrium (HRA) during the Post-JR (730 ms of cycle length) resulted in significant overdrive suppression of the JR, as the return cycle length was $800 \mathrm{~ms}, 70 \mathrm{~ms}$ longer than the cycle length of the PostJR (Fig 5). This RF application resulted in successful slow pathway ablation. All Post-JR episodes with a long duration (patient nos 8-10) demonstrated similar electrophysiologic features and time course as this representative case.

\section{Clinical Significance of the Emergence of the Post-JR}

Out of 50 RF current deliveries with a successful outcome, Post-JR was present in 9 applications, whereas out of 186 unsuccessful RF current deliveries, Post-JR was present in only 6 applications. Consequently, the sensitivity and specificity of the Post-JR in predicting a successful CA were $18 \%$ and $97 \%$, respectively, and the positive predictive value was $60 \%$. In comparison with that of JR during RF delivery, Post-JR had less sensitivity, but greater specificity, and a positive predictive value as a predictor of a 


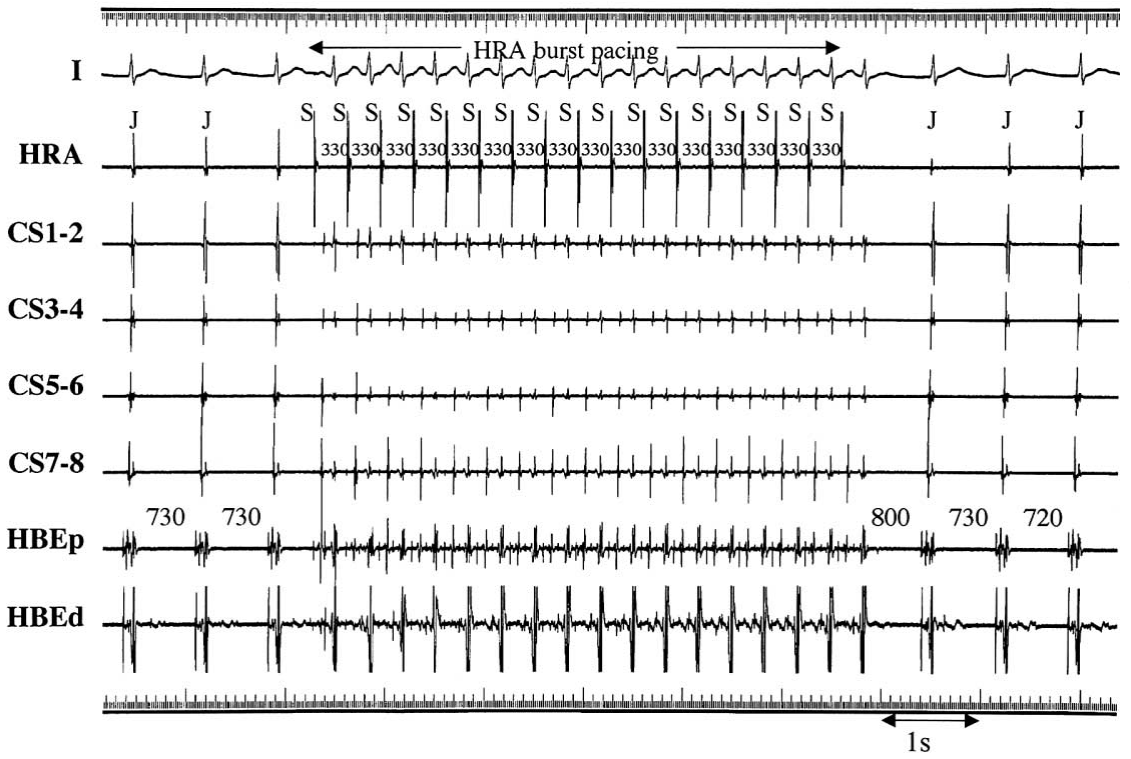

Fig 5. Representative recording of overdrive suppression of the long-term Post-JR by rapid atrial pacing. The A-A interval of the His bundle region immediately after cessation of the rapid atrial pacing $(330 \mathrm{~ms}$ of cycle length) was $800 \mathrm{~ms}$, and was $70 \mathrm{~ms}$ longer than the cycle length of the Post-JR.
Total time span

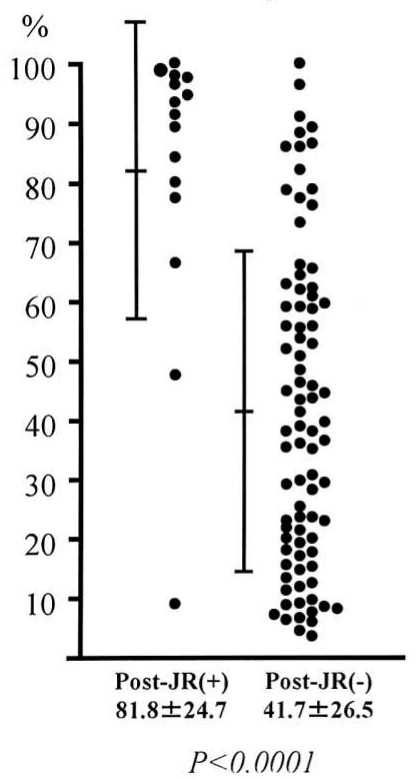

Longest duration of

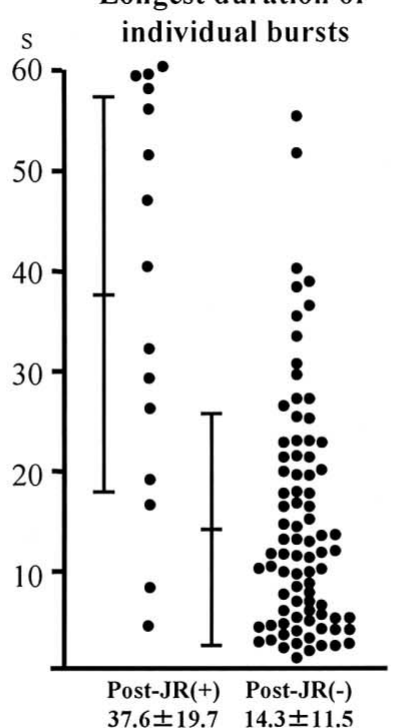

$P<0.0001$

successful CA outcome.

The clinical features of the JR observed during RF deliveries that were followed by persistent Post-JR $(n=15)$ were compared with those of the JR not followed by Post-JR $(\mathrm{n}=109)$. As shown in Fig 6, JR during RF current delivery followed by Post-JR had a greater total time span during which the JR appeared $(82 \pm 25$ vs $42 \pm 27 \%, \mathrm{p}<0.005)$ than the RF not followed by Post-JR, and a significantly longer duration of individual bursts of JR (38 \pm 19 vs $21 \pm 15 \mathrm{~s}$, $\mathrm{p}<0.001)$. The mean cycle length of the JR during the RF delivery was similar for both groups ( $568 \pm 153$ vs $600 \pm 161$ $\mathrm{ms})$.

Ventriculoatrial (VA) block in at least 1 or more junctional beats during RF current delivery was documented in 4 of 15 RF deliveries (27\%) with Post-JR, but in only 11 of 109 RF deliveries (10\%) without Post-JR ( $\mathrm{p}=0.15)$. Two out of 4 RF applications with Post-JR resulted in selective fast pathway ablation, whereas none of the applications without Post-JR eliminated the conduction over the fast

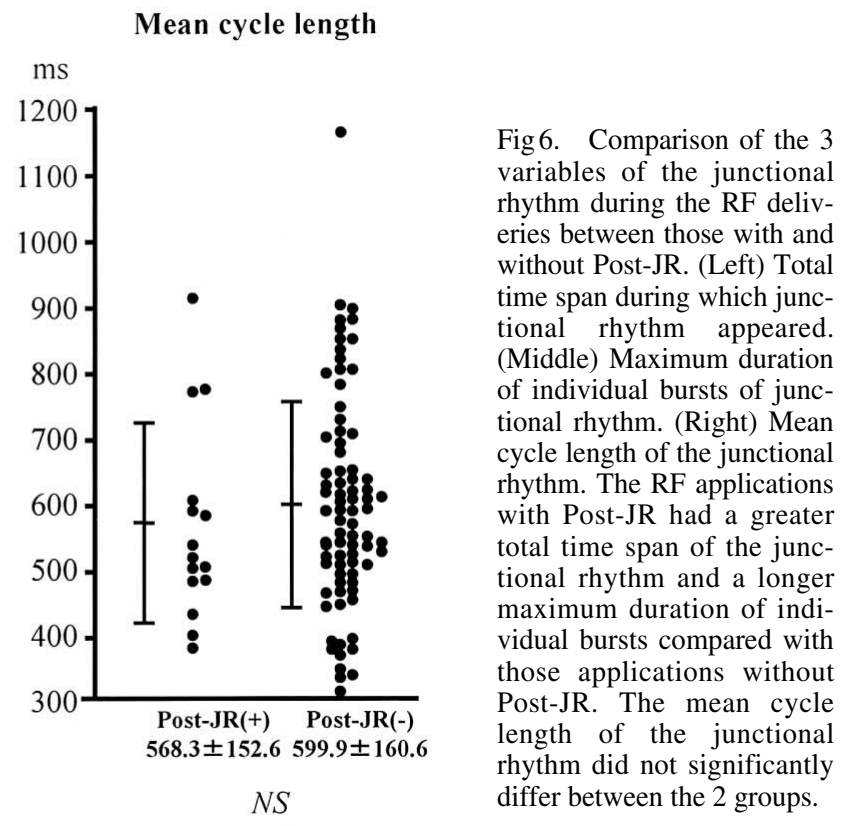

pathway. In the 2 patients with fast pathway ablation (patients no. 1 and 5 in Table 1), the ventriculoatrial block was maintained during the short-term Post-JR. None of the RF applications, including both with and without Post-JR, resulted in inadvertent permanent $\mathrm{AV}$ block that required pacemaker implantation.

\section{Discussion}

The main findings of the present study were as follows.

(1) Accelerated JR remained after termination of the RF current delivery (Post-JR) for CA of AVNRT in approximately $20 \%$ of the patients and $6 \%$ of the RF current applications.

(2) The Post-JR showed a spontaneous rate deceleration over the time-course during the post-RF period and underwent an overdrive suppression after the application of rapid atrial pacing. Furthermore, it was observed that the Post-JR was eventually terminated by being overridden by 
sinus rhythm rather than terminated abruptly, as shown in Fig 4.

(3) The RF applications followed by Post-JR had a greater time span in which the JR appeared and a longer duration of individual bursts of JR during RF delivery, than in the RF applications not followed by the Post-JR.

(4) The Post-JR had less sensitivity in predicting successful CA compared to the JR during the RF applications (18\% vs $96 \%$ ), but had a greater specificity (97\% vs $59 \%)$ and positive predictive value (60\% vs $39 \%)$.

(5) The RF applications followed by Post-JR were frequently associated with VA block of junctional beats during RF delivery and occasionally resulted in fast pathway ablation.

\section{Electrophysiologic Mechanism of the Post-JR}

Mechanism of Short-Term Post-JR Until recently it has been suggested in clinical studies that accelerated JR during the RF applications is a reflection of the heating effect on the nodal or perinodal tissue. This phenomenon has also been postulated to be due to enhanced automaticity of AV nodal cells in response to thermal injury?,14 The underlying mechanism of junctional tachycardia was exclusively evaluated by Thibault et al using an in vitro animal model? They demonstrated that heat-induced junctional tachycardia is most likely due to heat-induced acceleration of normal automaticity caused by an increase in the slope of phase 4 depolarization and shortening of the action potential duration. Thus there is general consensus that JR during RF energy delivery results from thermally mediated enhanced automaticity.

Meanwhile, the mechanism of the production of heat by RF energy has been clarified. During RF energy delivery, a thin surface underneath the electrode-tissue interface is heated resistively while the surrounding tissue is heated conductively ${ }^{8-10}$ The temperature of the tissue surface promptly decreases after termination of the RF application, because of the immediate elimination of resistive heating. In contrast, the temperature of the relatively deep tissue temporarily remains higher than the surface tissue and radial heat conduction may continue even after termination of the RF delivery9,10 Therefore, from a theoretical point of view, JR caused by the heating effect on the nodal or peri-nodal tissue may remain after termination of the RF delivery, because the cells with enhanced automaticity may still have residual heat and may be heated conductively by the deeper tissue. However, there has not been either a clinical or experimental study focusing on the JR that remains after termination of the RF application (Post-JR). Although it was not referred to in the previous reports, the presence of PostJR with a relatively short duration is recognizable in their figures? 3 ,4 Similarly we demonstrated that Post-JR remaining only for a few seconds $(<10 \mathrm{~s})$ was observed in $5 \%$ of the successful ablation sites (14\% of the patients). Although actual data of the tissue temperature both during and after the RF application for ablation of AVNRT is lacking, the appearance of such short-term Post-JR could be attributed to the residual heating effect on the nodal or perinodal cells, because the Post-JR rate decelerated after termination of the RF delivery, leading to conversion to sinus rhythm, and was never resumed during the follow-up period.

Mechanism of Long-Term Post JR We had 3 RF deliveries in which a long-term Post-JR, sustained for longer than $1 \mathrm{~min}$, was recognized after successful RF current delivery. Because the Post-JR with a long duration gradu- ally slowed down over time after the RF delivery, and because it underwent significant overdrive suppression from rapid atrial pacing applied from the HRA, the electrophysiologic mechanism of the long-term Post-JR is also considered to be enhanced automaticity, similar to that for JR occurring during RF delivery. However, the mechanism underlying the protracted course of the Post-JR remains obscure. None of the patients with the long-term Post-JR had clinical documentation of any other tachyarrhythmias other than AVNRT, including accelerated junctional tachycardia, either before the ablation session or during the follow-up period. Therefore, it is unlikely that a preexisting abnormal focus in the AV junction was stimulated by the RF current delivery resulting in the appearance of Post-JR. As previously described, the RF energy leaves a heating effect on the deep tissue after termination of its application, but this effect has been shown to be sustained for less than 1 min?,10 Consequently, this phenomenon cannot be explained by the residual heating effect on the non-pathological focus/foci with spontaneous automaticity.

The non-paroxysmal form of junctional tachycardia has been shown to appear secondary to certain intercurrent clinical settings, such as open heart surgery, cryosurgical ablation, 15,16 acute myocardial infarction, ${ }^{17}$ digitalis intoxication and acute myocarditis 18 Kerr et al, in their clinical study, suggested that stretching and minor trauma in the region of the AV junction may be responsible for the appearance of junctional tachycardia after open heart surgery, because valve replacement requires considerable manipulation in this region, as compared with coronary artery bypass surgery, and concomitantly shows a higher incidence of junctional tachycardia. ${ }^{15}$ Hence, it is inferred that the RF energy directed at the AV junction may also create a transient abnormal focus/foci by some patho-physiologic effect.

In the present study, all the RF current applications that resulted in long-term Post-JR were directed at the posterior part of Koch's triangle where the parasympathetic fibers that innervate the AV node traverse ${ }^{19,20}$ Furthermore, all 3 RF deliveries with long-term Post-JR were applied during intravenous infusion of isoproterenol, which has been shown to increase the frequency of spontaneous tachycardia episodes and accelerate the tachycardia rate. ${ }^{15}$ Such modification of the autonomic tone of both the sympathetic and parasympathetic nerves may play a role in the presence and perpetuation of the Post-JR.

\section{Clinical Implication of the Appearance of Post-JR}

The present study has shown that successful RF applications eliminating AVNRT induced a significantly denser JR during the RF delivery than did the unsuccessful applications. This is almost consistent with a previous report by Jentzer et al, in which successful RF applications were associated with runs of junctional ectopy that were longer in duration, but did not differ in cycle length. In addition, we have shown that among the successful RF applications, RF applications followed by Post-JR were associated with a longer duration of JR during the energy delivery than those applications without Post-JR. From these observations, we suggest that the phenomenon of JR remaining after termination of the RF delivery might be a reflection of the intense effect of RF energy on the nodal or peri-nodal tissue. Correspondingly, we demonstrated that the presence of Post-JR had less sensitivity, but greater specificity, and a positive predictive value as a predictor of successful CA, 
compared with JR only seen during RF applications.

On the other hand, this phenomenon might be a harbinger of extended AV nodal injury (AV block) imposed by the RF application, as conduction block over the fast pathway more frequently resulted from the RF application followed by Post-JR, compared with the applications without Post-JR. Therefore, it is suggested that when the Post-JR is observed, additional or bonus RF current delivery should be avoided in order to decrease the risk of the development of AV block, which requires permanent pacemaker implantation.

\section{Acknowledgment}

The authors express their special gratitude to Mr John Martin for his linguistic assistance in the preparation of this manuscript.

\section{References}

1. Haissaguerre M, Gaita F, Fische B, Commenges D, Monteserrat P, dIvernois C, et al: Elimination of atrioventricular nodal reentrant tachycardia using discrete slow potentials to guide application of radiofrequency energy. Circulation 1992; 85: 2162-2175

2. Kalbfleisch SJ, Strickberger AS, Williamson B, Vorperian VR, Man C, Hummel JD, et al: Randomized comparison of anatomic and electrogram mapping approaches to ablation of the slow pathway of atrioventricular node reentrant tachycardia. J Am Coll Cardiol 1994; 23: $716-723$

3. Thakur RK, Klein GJ, Yee R, Stites HW: Junctional tachycardia: A useful marker during radiofrequency ablation for atrioventricular node reentrant tachycardia. J Am Coll Cardiol 1993; 22: 1706-1710

4. Jentzer JH, Goyal R, Williamson BD, Man C, Niebauer M, Daoud E: Analysis of junctional ectopy during radiofrequency ablation of the slow pathway in patients with atrioventricular nodal reentrant tachycardia. Circulation 1994; 90: 2820-2826

5. Boyle NG, Anselme F, Monahan K, Papageorgious P, Zardini M, Zebede J, et al: Origin of junctional rhythm during radiofrequency ablation of atrioventricular nodal reentrant tachycardia in patients without structural heart disease. Am J Cardiol 1997; 80: 575-580

6. Wathen M, Natale A, Wolfe K, Yee R, Newman D, Klein G: An anatomically guided approach to atrioventricular node slow pathway ablation. Am J Cardiol 1992; 70: 886-889

7. Thibault B, de Bakker JMT, Hocini M, Loh P, Wittkampf FHM, Janse MJ: Origin of heat-induced accelerated junctional rhythm. $J$
Cardiovasc Electrophysiol 1998; 9: 631-641

8. Haines DE, Watson DD: Tissue heating during radiofrequency catheter ablation: a thermodynamic model and observations in isolated perfused and superfused canine right ventricular free wall. PACE 1989; 12: 962-976

9. Wittkampf FHM, Nakagawa H, Yamanashi WS, Imai S, Jackman WM: Thermal latency in radiofrequency ablation. Circulation 1996; 93: $1083-1086$

10. Wittkampf FHM, Simmers TA, Hauer RNW, de Medina EOR: Myocardial temperature response during radiofrequency catheter ablation. PACE 1995; 18: 307-317

11. Kobayashi Y, Ino T, Miyauchi Y, Kawaguchi N, Ogura H, Ohmura $\mathrm{K}$, et al: Curative percutaneous catheter ablation for various supraventricular and ventricular tachyarrhythmias. J Nippon Med Sch 1997; 64: 546-565

12. Josephson ME: Clinical cardiac electrophysiology: Techniques and interpretations, 2nd edn. Philadelphia: Lea \& Febiger, 1993

13. Jackman WM, Beckman KJ, McClelland JH, Wang X, Friday KJ, Roman CA, et al: Treatment of supraventricular tachycardia due to atrioventricular nodal reentry by radiofrequency catheter ablation of slow-pathway conduction. N Engl J Med 1992; 327: 313-318

14. Epstein LM, Lesh MD, Griffin JC, Lee RJ, Scheinman MM: A direct midseptal approach to slow atrioventricular nodal pathway ablation. PACE 1995; 18: 57-64

15. Kerr CR, Mason MA: Incidence and clinical significance of accelerated junctional rhythm following open heart surgery. Am Heart $J$ 1985; 110: 966-969

16. Kerr CR, Gallagher JJ, Cox JL, Smith WM, Sterba R: Accelerated junctional tachycardia at a rate of 190 beats/min following cryosurgery and aneurysmectomy for ventricular tachycardia: A case report. PACE 1982; 5: 442-454

17. Konecke LL, Knoebel SB: Nonparoxysmal junctional tachycardia complicating acute myocardial infarction. Circulation 1972; 45: 367-373

18. Gonzalez RP, Scheinman MM: Paroxysmal junctional and fascicular tachycardia in adults: Clinical presentation, course, and therapy. In: Zipes DP, Jalife J, editors. Cardiac electrophysiology: From cell to bedside. Philadelphia: WB Saunders, 1995: 691-698

19. Ardell JL, Randall WC: Selective vagal innervation of sinoatrial and atrioventricular nodes in the canine heart. Am J Physiol 1986; 251: $\mathrm{H} 764-\mathrm{H} 773$

20. Kay GN, Epstein AE, Dailey SM, Plumb VJ: Selective radiofrequency ablation of the slow pathway for the treatment of atrioventricular nodal reentrant tachycardia: Evidence for involvement of perinodal myocardium within the reentrant circuit. Circulation 1992; 85: $1675-1688$ 